\title{
CONFLICTOS ENTRE DERECHOS Y PONDERACIÓN. POR QUÉ LOS JUECES NO DEBERÍAN ABANDONAR LA PERSPECTIVA DEONTOLÓGICA*
}

\author{
Marina Velasco \\ Universidade Federal de Rio de Janeiro
}

RESUMEN. La idea de que los derechos fundamentales deben ser «ponderados» cuando entran en conflicto goza de una amplia y creciente aceptación. Para Robert ALEXY, el más influyente defensor de la ponderación, ello es inevitable debido a que los derechos tienen la forma de principios y estos tienen que ser entendidos como mandatos de optimización. En el texto argumento que para tomar una decisión racional en tales casos no es inevitable ponderar. Para ello distingo dos formas básicas que una decisión racional puede adoptar en los casos en que reconocemos un conflicto entre principios: deontológica e teleológica; exploro las implicaciones que se siguen de ambas perspectivas y pongo en duda que el procedimiento teleológico de la ponderación sea el más adecuado en tales casos. Concluyo afirmando que en los casos de conflicto entre derechos fundamentales los jueces no deberían abandonar la perspectiva deontológica que adoptan en las decisiones judiciales en general, a diferencia de los ciudadanos, quienes pueden y deben ponderar sobre valores y sobre fines.

Palabras clave: ponderación, conflictos entre derechos, reglas y principios.

\section{Conflicts between Basic Rights and Balancing: Why judges should not abandon the deontological stance}

ABSTRACT. The notion that the application of basic rights requires «balancing» is widely and increasingly accepted. For Robert ALEXY, the most influential philosopher of law advocating balancing, that is unavoidable because rights have the form of principles and these must be understood as "optimization requirements». I argue that balancing is not unavoidable for adopting a rational decision in such cases. I describe two basic patterns that a rational decision may follow when we recognize a conflict between principles: deontological and teleological; explore the implications that follow from both perspectives and argue against the idea that the teleological procedure of balancing is the most appropriate in such cases. I conclude asserting that in cases of conflict between basic rights judges should not abandon the deontological stance that they must adopt everywhere in judicial decisions, differently from citizens, who can and must balance values and ends.

Keywords: Balancing, Conflict between rights, Rules and Principles.

* Fecha de recepción: 29 de octubre de 2015. Fecha de aceptación: 22 de septiembre de 2016. 
a idea de que los derechos fundamentales deben ser «ponderados» cuando entran en conflicto goza de una amplia y creciente aceptación. Muchos juristas consideran que el juicio de ponderación no solo es el método más apropiado para resolver conflictos entre derechos fundamentales sino que es el único método posible - no solamente para para decidir casos en los que hay conflictos entre derechos fundamentales entre sí, sino también casos en los que hay un conflicto entre derechos fundamentales y bienes colectivos-. De hecho, el juicio de ponderación es cada vez más usado en las decisiones judiciales de las cortes constitucionales, especialmente en las cortes supranacionales de derechos humanos.

La situación se ve favorecida por el reconocimiento de un número creciente de conflictos normativos. Ciertamente, los conflictos normativos no constituían algo que mereciera la atención en la época de la gran codificación jurídica. Pero en las democracias constitucionales de las últimas décadas los códigos - conformados por normas que tienen la forma de reglas — tienen cada vez menos peso en la argumentación jurídica. En todas las instancias y ramas del derecho los conflictos tienden a ser planteados en términos de derechos fundamentales — que son normas que tienen forma de principios. El fenómeno es ampliamente reconocido y puede ser caracterizado como una descodificación del derecho o una constitucionalización del derecho, según se mire el proceso en una u otra dirección. Si dejamos de lado algunos detalles doctrinarios locales, no es difícil concordar con la constatación de que «Vivimos en la era de la ponderación constitucional [Constitutional Balancing]» ${ }^{1}$. Algunos consideran que el juicio de ponderación es «una pieza esencial del constitucionalismo contemporáneo (o Neoconstitucionalismo)»².

En este artículo quisiera realizar una crítica al uso extendido del juicio de ponderación en las decisiones judiciales. Me interesa reflexionar sobre la racionalidad que debe guiar las decisiones judiciales, pero la crítica que formulo no consiste en afirmar que la ponderación sea un procedimiento irracional ${ }^{3}$. La ponderación es perfectamente racional; «racional» en el sentido de la racionalidad medio-fin. Lo que pongo en duda

1 S. GARDBAUM, «A Democratic Defense of Constitutional Balancing», Law and Ethics of Human Rights 4, núm. 1 (2010). Lo que en la tradición del Common Law se llama Balancing corresponde a lo que en la tradición de Civil Law se entiende por proporcionalidad [Verhältnismassigkeit] en sentido estricto. Vid. Th. A. ALEINIKOFF, «Constitutional Law in the age of Balancing», Yale Law Journal, 96, núm. 5 (1987); M. KumM, «Constitutional rights as principles: On the structure and domain of constitutional justice. A review essay on A Theory of Constitutional Rights», International Journal of Constitutional Law, 2, núm. 3 (2004). Para interesantes críticas al uso de la ponderación, vid. B. CALI, «Balancing Human Rights? Methodological Problems with Weights, Scales and Proportions,» Human Rights Quarterly, 29, núm. 1 (2007) y S. TsaKYRAKIS, «Proportionality: An assault on Human Rights?», International Journal of Constitutional Law, 7, núm. 3 (2009). No deja de ser curioso que la ponderación sea tomada como modelo de razonamiento sobre los derechos, cuando el éxito de los derechos en el pensamiento político-moral en las últimas décadas se ha basado, en gran medida, en el hecho de ser entendidos como estableciendo límites a la ponderación (utilitarista), como «triunfos» frente a consideraciones de utilidad, según la metáfora de DwORKIN.

${ }^{2}$ L. Prieto Sanchís, Justicia constitucional y derechos fundamentales, Madrid, Trotta, 2003, 216. Para una interesante presentación que muestra la importancia creciente de la argumentación jurídica una vez que el modelo de la codificación entra en crisis, vid. M. LA TORRE, «Theories of Legal Argumentation and Concepts of Law. An Approximation», Ratio Juris, 15, núm. 4 (2002).

${ }^{3}$ La crítica sobre la irracionalidad de la ponderación suele ser poco clara. Hay que reconocer que en el caso de HABERMAS, no fue formulada de manera muy feliz (J. HABERMAS, Faktizität und Geltung: Beiträge zur Diskurstheorie des Rechts und des Demokratischen Rechtsstaats, Frankfurt, Suhrkamp, 1992, 315-316). A mi juicio, el problema no es la irracionalidad del procedimiento, sino de la decisión llevada a cabo por el procedimiento cuando se aplica a normas entendidas como valores, como argumentaré después. 
es que esa concepción de la racionalidad medio-fin sea apropiada para guiar la decisión judicial en los casos en que hay un conflicto entre derechos fundamentales.

La pregunta central que formulo es simple: dado que todo el mundo acepta que la perspectiva del juez cuando decide una sentencia debe ser en general deontológica (salvo que enfrente una catástrofe, tal vez), ¿por qué cuando este mismo juez reconoce que hay un conflicto entre derechos debería abandonar esa perspectiva deontológica y pasar a ponderar valores? No he encontrado ninguna respuesta convincente a esta pregunta por parte de los que defienden el uso del juicio de ponderación. Presumiblemente porque suponen que la ponderación es inevitable en estos casos. Trataré de mostrar que no es inevitable ponderar para tomar una decisión racional en estos casos, y que en el caso específico de la decisión judicial, cuanto más los jueces eviten ponderar, mejor será la decisión en términos de racionalidad jurídica.

Para demostrar esta tesis caracterizaré las dos formas básicas que el razonamiento práctico de un agente decisor puede adoptar en casos de conflicto entre principios prácticos en general: la forma teleológica y la forma deontológica. Y argumentaré contra la idea de que la forma teleológica de resolver el conflicto - la ponderación de valores - sea el único procedimiento adecuado para resolver racionalmente un conflicto entre principios prácticos, sean morales o jurídicos. En síntesis, quisiera defender que el juicio de ponderación:

a) no es el único procedimiento racional para decidir un conflicto entre principios, y que por tanto no es inevitable usarlo;

b) no es el más apropiado en todas las circunstancias en que hay un conflicto entre principios; y que

c) no es el más apropiado especialmente en el caso de la decisión judicial que enfrenta un conflicto entre derechos fundamentales.

Antes de tratar de defender estas tesis, recordaré la estructura del juicio de ponderación en su versión más difundida, la de Robert ALEXY, y caracterizaré los dos escenarios que representan de manera diferente el conflicto entre principios prácticos: el teleológico y el deontológico.

\section{EL JUICIO DE PONDERACIÓN}

Los conflictos entre derechos son conflictos entre normas que tienen la forma de principios y no de reglas. Quienes consideran inevitable la ponderación suelen representar el conflicto como un conflicto entre valores. Así, por ejemplo, para Robert ALEXY, el filósofo del derecho más influyente defensor de la ponderación, concebir los derechos fundamentales como principios significa entenderlos como «mandatos de optimización» y, por esa misma razón, como aplicables exclusivamente por medio de un juicio de ponderación. Entendidos de esa manera, los principios son normas que - a diferencia de las reglas- no determinan exactamente lo que debe hacerse sino que ordenan «que algo sea realizado en la mayor medida posible, según las posibilidades jurídicas y fácticas existentes» ${ }^{4}$. Para establecer esa «mayor medida posible» es nece-

${ }^{4}$ R. ALEXY, Theorie der Grundrechte, Frankfurt, Suhrkamp, 1986. 
sario confrontar el principio en cuestión con las exigencias que plantean principios o valores opuestos.

El juicio de ponderación es un juicio de valor comparativo. Lo que se compara es el grado de importancia de la realización de un principio y el grado de interferencia o de no satisfacción del otro:

cuanto mayor es el grado de no satisfacción de [o interferencia en] un principio, mayor debe ser la importancia en satisfacer o realizar el otro 5 .

Aunque no usa valores numéricos, la ponderación tiene la forma de un juicio costobeneficio. Se trata de determinar si las ventajas que se siguen de la satisfacción de un principio compensan las pérdidas que se siguen de la interferencia en el otro. El juicio de ponderación representa una exigencia de maximizar la realización de los valores involucrados en el conflicto y, por tanto, de minimizar todo tipo de interferencia en los derechos fundamentales. Es importante percibir que, para esta perspectiva, todo tipo de interferencia es vista como negativa, no importa las razones por las cuales la interferencia es realizada.

Como es obvio, la necesidad de ponderar en los casos de conflicto se sigue de la concepción específica de los principios que ALEXY defiende. La «conexión lógica» que ALEXY afirma que existe entre derechos y ponderación no se sigue, sin más, de entender que los derechos fundamentales tienen forma de principios; se sigue de entender que todos los principios tienen la forma de mandatos de optimización ${ }^{6}$. Su teoría sería válida si para justificar una decisión en el caso de un conflicto entre principios siempre fuera necesario ponderar los valores involucrados en el conflicto. Pero ese no es el caso. Todo depende de la concepción del razonamiento práctico que se presuponga.

\section{DOS ESCENARIOS PARA EL CONFLICTO DE PRINCIPIOS}

En los conflictos morales se muestra de modo dramático el tipo de colisión normativa que nos interesa examinar. A veces es llamada colisión «externa», «situacional» o «contingente», porque no se manifiesta en las relaciones entre las normas en abstracto, sino solo en la situación concreta de aplicación: dos normas válidas conducen a dos jui-

5 Ibid. Basado en la jurisprudencia del Tribunal Constitucional alemán, el juicio de ponderación es parte del llamado Principio de Proporcionalidad. Este aparece como un conjunto articulado de tres subprincipios: el de idoneidad, el de necesidad, y el de proporcionalidad en sentido estricto (este último es el juicio de ponderación). Cada uno de los tres subprincipios expresa una exigencia gradual que toda interferencia en los derechos fundamentales tiene que cumplir para poder considerarse justificada:

1. según el subprincipio de idoneidad, toda interferencia en los derechos fundamentales debe ser idónea o adecuada para alcanzar el fin (constitucionalmente legítimo) que se propone;

2. según el subprincipio de necesidad, la interferencia en los derechos fundamentales debe ser necesaria, en el sentido de no existir otra alternativa, tan eficaz como la primera pero menos gravosa para los otros principios o derechos afectados;

3. según el subprincipio de proporcionalidad en sentido estricto, las ventajas que se obtienen con la interferencia en el derecho fundamental deben compensar los sacrificios que implican para sus titulares y para la sociedad en general.

${ }^{6}$ AlEXY entiende por principios lo que DwORKIN entendía por directrices (policies). Además de distinguir entre reglas y principios en general, DWORKIN distinguía entre principios, en sentido estricto, y directrices (policies), entendiendo estas últimas como normas que establecen fines a ser alcanzados, i. e., exigen la realización de un estado de cosas, razón por la cual siempre pueden ser realizadas de forma gradual. Vid. R. DwORKIN, Taking Rights Seriously, Harvard University Press, 1978, 22. 
cios de deber singulares incompatibles y superpuestos, a dos obligaciones imposibles de ser cumplidas simultáneamente.

Tomemos el ejemplo más usado para discutir el tema, y que — desde que David Ross lo introdujo se ha transformado en el ejemplo modelo- ${ }^{7}$. Prometí a un amigo ir a su fiesta, pero ahora sucede que otro amigo está enfermo y reclama mi presencia. En mi sistema normativo rigen simultáneamente dos obligaciones: se debe cumplir las promesas y se debe ayudar a los amigos en caso de necesidad. En abstracto no hay ninguna contradicción entre ambas normas. Ellas son perfectamente compatibles. Sin embargo, en determinadas situaciones pueden entrar en conflicto. Dado que el conflicto no puede ser resuelto declarando inválida a una de las normas, es necesario decidir cuál de ellas va a tener prioridad en las circunstancias concretas.

Lo que hace especialmente difícil este tipo de conflicto normativo es que no puede ser resuelto apelando a algún criterio que permita colocar en abstracto las normas en un orden lexicográfico. Esa es justamente la razón por la cual el tema ha sido tan discutido en la filosofía del derecho en los últimos años. Porque los criterios tradicionalmente aplicados en el derecho para la resolución de antinomias no pueden ser aplicados en estos casos de conflicto entre principios, precisamente porque las normas no tienen la forma de reglas: ni el criterio jerárquico (la ley superior deroga la ley inferior), ni el cronológico (la ley posterior deroga la ley anterior), ni el de especialidad (la ley especial deroga la ley general). Tenemos aquí un conflicto entre dos normas válidas que continúan siendo válidas después de tomada la decisión. No es posible definir en abstracto la contradicción, ni prever con certeza las situaciones en las cuales las normas entrarán en colisión. Solamente en el caso concreto podremos justificar la opción por la prioridad de una norma sobre la otra. Además, la norma a la que se dio prioridad en una situación concreta puede no ser la misma escogida en otra situación en la que las mismas dos normas vuelven a colidir. Es por eso que — se afirma—es necesario ponderar para decidir lo que, dadas las circunstancias, sería correcto hacer.

Hay un sentido en que ello es obvio, si con «ponderar» entendemos la consideración y evaluación de la importancia de las razones relevantes. Necesitamos reflexionar y justificar la decisión a la luz de las diversas exigencias que nos son puestas por la situación. Pero la idea de ponderar en el sentido de «sopesar» puede terminar enmascarando el verdadero funcionamiento de las razones.

Con la idea de una ponderación (en inglés, balancing o weighing; en alemán, Abwägung) suele entrar en escena una poderosa metáfora, que es por lo menos tan antigua como la idea justicia: la metáfora del peso, y concomitantemente, de una balanza que establece el peso. Se trata de una metáfora irresistible, pero no deja de ser una metáfora, y por eso tiene que ser siempre interpretada. Decidir algo racionalmente significa poder justificar la decisión sobre la base de razones, pero las razones son enunciados lingüísticos, y los enunciados lingüísticos no pesan. ¿Cómo medir el peso de las razones?

En principio, no hay problema en dar el nombre de «ponderación» al procedimiento por medio del cual evaluamos la relevancia (el «peso») de las razones que se confrontan. Algún nombre tenemos que dar a eso que hacemos cuando tenemos que

7 D. Ross, The Right and the Good, Indiana, Hackett Publishing Company [1930] 1988. 
decidir qué hacer y evaluamos diferentes tipos de razones para justificar la elección. Nada parece más natural en este contexto que hacer una distinción entre, por ejemplo, razones prima facie válidas a favor de realizar una acción y razones «ponderadas». La cuestión relevante a ser discutida es cómo se hace eso, o sea, cuál es la forma de razonamiento práctico usada en estos casos.

Tal como adelanté, creo que podemos distinguir dos formas básicas de razonamiento práctico que el agente decisor puede adoptar: teleológica y deontológica. Mientras que en el primer caso se trata de llegar a una decisión sopesando bienes o valores, en el segundo caso se trata de producir un argumento que muestre que la decisión «se ajusta» al caso a la luz del sistema normativo presupuesto. En el primer caso la decisión es consecuencialista y obedece a la lógica «del bien». Se trata de encontrar, a la luz de los valores en conflicto, la mejor solución, la óptima. En el segundo caso, se procura una solución que pueda considerarse «correcta» a la luz de las normas presuntamente aplicables; el razonamiento obedece en este caso a la lógica «del deber» ${ }^{8}$.

Quisiera presentar más en detalle la perspectiva deontológica, porque tal vez sea menos obvia para el sentido común 9 . Quien se mueve en la perspectiva teleológica puede no ver mucha diferencia entre una deliberación en primera persona sobre lo que, en una determinada situación, «sería bueno hacer» o «sería correcto hacer», pero la perspectiva deontológica ve aquí dos cuestiones bien diferentes: la cuestión del bien y la cuestión de lo correcto. Al discutir el ejemplo mencionado entre las presuntas obligaciones para con los dos amigos, dice Ross:

Y cuando pienso que es correcto aliviar el dolor al costo de no cumplir la promesa, no es porque pienso que voy a producir un bien mayor, sino porque pienso que en las circunstancias, ese el deber que es más propiamente un deber ${ }^{10}$.

Personalmente no me queda del todo clara en sus detalles la posición de Ross, pero aquí solo me interesa percibir la perspectiva que presenta del agente decisor. Recordemos que fue David Ross, además, quien introdujo la noción de obligación (o deber) prima facie en oposición a la obligación (o deber) definitivo, y lo hizo justamente con la intención expresa de dar cuenta de la situación de conflicto de una manera mejor que la perspectiva consecuencialista. La decisión en el conflicto surge, para Ross, de una evaluación no consecuencialista, y por tanto deontológica, de las razones para actuar, de una «ponderación» (si así queremos llamarla) que no consiste en sopesar los valores en juego en la situación, sino en determinar una acción como la correcta o debida en las circunstancias de que se trata.

8 Consecuencialistas son llamadas las teorías éticas que sostienen la prioridad de lo bueno sobre lo correcto. Lo correcto, para un consecuencialista, no solo está subordinado a lo bueno sino que ni siquiera se define de manera independiente de lo bueno: para un consecuencialista lo correcto es maximizar lo bueno. Deontológicas, por el contrario, son llamadas las teorías éticas que sostienen la prioridad de lo correcto sobre lo bueno. En este caso, lo correcto no solo no está subordinado a lo bueno sino que establece restricciones a la persecución de lo bueno.

9 Y porque, además, suele ser malinterpretada, o confundida con formalismo o, en el caso del deontologismo kantiano, con una obediencia ciega al deber o un rigorismo que se aferra fanáticamente a la letra de la ley. Espero quede claro que no es nada de eso a lo que me refiero cuando hablo de «perspectiva deontológica». Llamo a la perspectiva deontológica porque da primacía al concepto de deber, pero está muy lejos del rigorismo, justamente porque hay en esa perspectiva una sensibilidad mayor a los rasgos de las situaciones que en la perspectiva teleológica, como intentaré mostrar.

10 D. Ross, $i d$., 18, mi traducción y énfasis. 
Veamos cómo se presenta el escenario del conflicto para otra perspectiva deontológica, la kantiana. Puede parecer paradójico preguntarse cómo KANT se representa la situación de un conflicto normativo, porque —en rigor- el único lugar en toda su obra en que hace referencia a un conflicto de obligaciones es para negar que este pueda existir ${ }^{11}$. Pero es importante ver por qué lo dice. No puede haber conflicto de obligaciones, afirma KANT, porque objetivamente el conflicto no existe. El conflicto está en el sujeto, y es un conflicto entre razones para estar obligado [Verplichtungsgründe]. La obligación propiamente dicha - el juicio de deber definitivo- surge de la deliberación; no existe con anterioridad a ella. Por eso no puede haber para KANT, hablando estrictamente, conflicto de deberes:

No obstante, en un sujeto y en la regla que él se prescribe pueden muy bien encontrarse dos razones de la obligación (rationes obligandi), de las que una u otra es, sin embargo, insuficiente para obligar (rationes obligandi non obligantes), porque entonces una no es deber. - Si dos razones semejantes se oponen entre sí, la filosofía práctica no dice entonces que la obligación más fuerte conserva la supremacía (fortior obligatio vincit), sino que la razón más fuerte para obligar conserva el puesto (fortior obligandi ratio vincit) $)^{12}$.

El conflicto, para KANT, no es entre obligaciones, sino entre razones para obligaciones. Si el conflicto fuera entre obligaciones ya conformadas e independientes, tendría que ser resuelto por medio de una ponderación que atribuyera un peso diferente a cada una. En un conflicto de ese tipo «la obligación más fuerte vence». En cambio, en un conflicto entre razones para obligaciones «la razón más fuerte» no vence de la misma manera. KANT dice que ella «conserva el puesto»o, podríamos decir, «domina el campo» ${ }^{13}$. La metáfora sugiere que la razón más débil no puede ocupar el campo de la misma manera. Ella no tiene peso efectivo en las circunstancias, ni siquiera un peso menor. La obligación que surge de la deliberación es una razón decisiva para actuar que apaga a las razones opuestas. Eso no significa que la razón más débil tenga que ser ignorada para siempre. Ella puede dar lugar a una deliberación adicional. Para esta perspectiva, las razones están siempre disponibles en los rasgos que reconocemos como relevantes en las situaciones; las obligaciones tenemos que determinarlas. En eso consiste el razonamiento práctico.

Independientemente de la concepción kantiana, me interesa resaltar aquí algo más general. Y es que desde esa perspectiva deontológica es posible representarnos la situación deliberativa del conflicto entre principios como la de una tentativa de encontrar un tipo de acción que satisfaga de la mejor manera las múltiples exigencias y principios que se presentan como relevantes en la situación, y no de ponderar el peso de principios independientes ${ }^{14}$.

Las cosas se presentan de manera bien diferente para un agente decisor que opera solamente con la forma de razonamiento teleológico. Cuando hay un conflicto entre

${ }^{11}$ Con excepción del opúsculo «Sobre el presunto derecho a mentir por amor a la humanidad», que no voy a considerar aquí. En la interpretación que desarrollo me apoyo en B. HERMAN, «Obligation and Performance», in The Practice of Moral Judgment, Harvard University Press, 1993, 159-183.

12 I. KANT, La metafísica de las costumbres, trad. Adela CORTINA, Madrid, Tecnos, 1989, 31.

13 «... behalt den Platz» (Ak. VI, 224: «Wenn zwei solcher Grunde einander wiederstreiten, so sagt die praktische Philosophie nicht: dass die starkere Verbindlichkeit die Oberhand behalte [...] sondern der starkere Verpflichtungsgrund behalt den Platz»).

${ }_{14}$ O. O'NeILL, «Normativity and Practical Reason», in Journal of Moral Philosophy, vol. 4 (3), 2007, 393 405. Vid. también, de la misma autora, «Principles, practical judgment and institutions», in Bounds of Justice, Cambridge University Press, 2000, 50-64. 
dos obligaciones, él deberá «pesar» razones independientes y juzgar qué sea mejor o peor hacer. Hacer lo correcto será hacer lo mejor: maximizar la realización de las alternativas. Muchas veces la obligación que no fue satisfecha tiene un efecto residual. Era uno de los valores en conflicto, y continúa ejerciendo su peso. Fácilmente surge en este escenario una metáfora económica. La obligación que no fue realizada —que en este escenario era propiamente una obligación, y no una razón para obligación- tiene que ser compensada de alguna manera, ya que el agente no la cumplió. Hubo una omisión y, por tanto, hay una deuda que pagar. Un agente responsable debe «hacer el balance» ${ }^{15}$. En este escenario, justificar racionalmente una decisión siempre podrá ser una cuestión de grado. Habrá un más y un menos, una aproximación mayor o menor a un fin y, eventualmente, una compensación de un mal menor por un bien mayor.

\section{POR QUÉ LOS JUECES NO DEBERÍAN ABANDONAR EL PUNTO VISTA DEONTOLÓGICO}

Hemos caracterizado a grandes rasgos las dos formas básicas que, a nuestro juicio, el razonamiento práctico de un agente decisor puede adoptar en casos de conflicto entre principios prácticos en general. Aunque superficial, esta somera caracterización nos permitirá comparar los dos escenarios, reflexionar sobre la racionalidad de la toma de decisión y del agente decisor presupuestas en cada caso y sacar algunas consecuencias para pensar - en el caso específico de la argumentación jurídica- en el tipo de racionalidad que debería guiar la decisión judicial en casos de conflicto entre derechos fundamentales.

En primer lugar, hay una diferencia muy importante entre las dos perspectivas, que es previa a la deliberación, y que tiene que ver con cómo cada posición configura el escenario en el que se delibera. Para la perspectiva teleológica la situación de conflicto ya está configurada desde el vamos como tal. Todo lo que aparenta ser un conflicto es un conflicto. Se reconoce un conflicto de deberes como punto de partida. Ese no es el punto de partida para la perspectiva deontológica sino, en todo caso, un punto de llegada. Para esta perspectiva hay un conflicto de razones para el sujeto que delibera, pero no de deberes (por lo menos no de deberes definitivos). Habrá que determinar en la deliberación cuál de esas razones se configura como un deber (definitivo).

Como es obvio, esto tiene consecuencias muy importantes para la argumentación jurídica a la hora de conceptualizar los conflictos de derechos que tienen que ser decididos por los jueces. Para comenzar, hay una gran diferencia entre hablar de un

15 B. HeRMAN, op. cit., 177, se refiere, en este contexto, a lo que llama problema de las «tres R»: remordimiento, reparación y resto (remorse, restitution y remainders). Es importante percibir que para la posición teleológica estos conceptos se justifican porque el agente ha hecho algo incorrecto. Por cumplir una obligación ha dejado de cumplir otra, o, en el caso de los derechos, para realizar un derecho se ha restringido otro. Para la posición deontológica, en cambio, el remordimiento o la restitución no tendrían razón de ser, ya que se considera que el agente ha realizado la acción correcta. Sin embargo, el agente puede reconocer que, luego de haber actuado y becho lo correcto, la nueva situación plantea una nueva exigencia en su deliberación. Por ejemplo, para retornar al ejemplo de Ross, justificar al primer amigo el no cumplimiento de la promesa, o al segundo amigo el no responder a su pedido, dependiendo de la decisión que haya sido tomada en el conflicto, no significa reconocer que se ha hecho algo malo, sino tener en cuenta que el otro tenía una expectativa con respecto a nuestro comportamiento que no se realizó. 
conflicto entre derechos y hablar de un conflicto entre pretensiones de derecho. Al fin y al cabo, que se trate de un verdadero conflicto de derechos es algo que tendría que ser mostrado. Cuando aceptamos que dos derechos están en conflicto ello implica que aun cuando un derecho pueda al final no ser reconocido o garantizado, era de todos modos un derecho real que estaba en juego, y no solamente una pretensión que tenía que ser considerada para determinar qué derechos había en juego. Para la perspectiva teleológica todo lo que aparece como un conflicto entre derechos es un conflicto entre derechos. El problema de aceptar que todo lo que aparece como un conflicto es un conflicto no es solamente que muchos conflictos entre derechos puedan venir a revelarse como aparentes, sino también que puede haber más derechos en juego en la situación que se está juzgando, derechos que simplemente se pasan por alto por atenerse al conflicto entre dos derechos tal como aparece configurado en el inicio.

Esta distinción entre los dos escenarios del conflicto nos lleva a poner en duda la inevitabilidad de la ponderación. La ponderación es inevitable solo para quien ya se representó una situación de conflicto en la que se plantean exigencias independientes y simultáneas; en el caso específico de un conflicto de derechos fundamentales: solo para quien entiende que los derechos ya estaban plenamente configurados antes de iniciar la deliberación decisoria. Nótese que si los derechos ya están plenamente configurados, es poco lo que la argumentación decisoria puede agregar, por eso se hace necesario ponderar. El papel que la argumentación desempeña en la decisión es mucho más importante para la perspectiva deontológica, porque se hace necesario caracterizar detalladamente la situación para determinar qué deberes (o derechos) hay en juego en la situación, y ello exige interpretar y concretizar los derechos ligándolos a la situación.

En segundo lugar, como ya apuntamos, las dos concepciones del razonamiento práctico divergen sobre el tipo de razones que fundamentan la decisión. La perspectiva teleológica, más fiel a la metáfora del sopesar, entiende que la decisión correcta es aquella que representa la mejor alternativa, calculada en función de un balance entre el bien y el mal que previsiblemente producirá la decisión. Por eso la hemos caracterizado como consecuencialista. Desde esta perspectiva, la decisión considerada «correcta» será aquella que maximiza la realización de los valores en conflicto. La perspectiva deontológica, por el contrario, entiende que la decisión racional a tomarse en la situación no se basa, en principio, en las (buenas) consecuencias previstas. Las normas en conflicto no se perciben primariamente como valores que deben ser realizados en la mayor medida posible. No se hace un cálculo costo-beneficio, ni se piensa en la compensación de un mal menor por un bien mayor, sino que se procura llegar a una decisión «correcta» (debida) en las circunstancias a la luz de las normas reconocidas como válidas y presuntamente aplicables en la situación.

¿Qué consecuencias se siguen de representar los principios en conflicto como valores, como lo hace la perspectiva teleológica, o considerarlos simplemente como normas abiertas (o sea, como normas que no tienen la forma de reglas sino de principios), como lo hace la perspectiva deontológica? ${ }^{16}$.

16 Es necesario tener cautela y no caracterizar la oposición entre deontologistas y teleologistas, sin más, en términos de la oposición entre normas y valores, porque el deontologista puede hablar el lenguaje de los valores y porque es innegable que las normas encarnan valores. La diferencia en las posiciones está en que para 
Si los principios son entendidos como valores, no hay necesariamente un ordenamiento entre ellos, salvo que se establezca una jerarquía. No necesito recordar en este contexto los problemas que se siguen de establecer en abstracto una jerarquía de valores que, justamente, es la que tiene que ser revisada en los casos en que reconocemos un conflicto. De eso estamos hablando. Los valores pueden formar una constelación pero no hay ninguna necesidad de que conformen un orden sistemático. En cambio, las normas tienen que concebirse ordenadas en un sistema para que podamos considerarlas como un conjunto de normas presuntamente aplicables en una situación.

Un problema adicional en la concepción de los principios de ALEXY es que no solo los concibe como valores, sino exclusivamente como valores a ser maximizados. Pero no todos los valores son de un tipo tal que exigen ser maximizados. Algunos valores manifiestamente exigen no ser violados, o ser respetados, no ser maximizados. Por ejemplo, el valor de igualdad. Tomemos, por caso, una formulación jurídica del principio de igualdad: «El Estado no podrá hacer ningún tipo de discriminación negativa basada en sexo, raza, religión, etc.». Damos el nombre de principio a esta norma a causa de la configuración abierta de sus condiciones de aplicación. Sin embargo, en la norma hay una descripción de una conducta prohibida que no es indeterminada y que no supone una realización gradual: la acción de discriminar negativamente. La exigencia es de un cumplimiento pleno. No tiene sentido pensar en un cumplimiento gradual (como si el principio pudiera significar algo así como «dependiendo de los principios que operen en sentido contrario, discrimine lo menos posible») ${ }^{17}$. ¿Qué significa la afirmación de que los principios tienen que ser realizados «en la mayor medida posible»? La idea de una realización máxima de los principios sugiere que si no hay principios que operen en sentido contrario ellos deberían ser realizados completamente. Pero eso no parece tener sentido en muchos casos. Por eso, la interpretación más plausible para la afirmación de que los principios deben ser realizados «en la mayor medida posible» parece ser que ellos deben ser realizados «en la medida correcta» $^{18}$.

el deontologista el conflicto se plantea en términos de un conflicto de normas (aunque estas encarnen valores), y la solución del conflicto —el ajuste de los «valores» que soluciona el conflicto- no es realizado por medio de una ponderación teleológica. DWORKIN, por ejemplo, muchas veces hablaba en términos de valores pero lo hacía, sin embargo, desde una perspectiva deontológica: la integridad siempre se opone a la ponderación. Vid., por ejemplo, en su último libro, el capítulo 11, donde opone explícitamente las dos estrategias para compatibilizar o armonizar principios: Balance and integrity. R. DwoRKIN, Justice for Hedgehogs, Cambridge (Mass.), Harvard University Press, 2011, 260 y ss.

17 Así lo apuntan M. Atienza y J. MANero, «Sobre Principios y Reglas», Doxa. Cuadernos de Filosofía del Derecho, núm. 10 (1991). Nótese que la igualdad puede ser la finalidad de una política (en el sentido de un estado de cosas a ser alcanzado de forma gradual) pero, justamente, se supone que una política dirigida a promover la igualdad no debe violar la igualdad entendida como derecho. Trato este tema en M. VeLASCO, ¿Qué es la justicia? Argumentos filosóficos sobre lo justo y lo injusto, Buenos Aires, Eudeba, 2011.

18 K. MÖLLER, «Balancing and the structure of constitutional rights», I.Con, vol. 5, núm. 3, 2007, 453 468. Otro problema para la posición de ALEXY es el de la compatibilidad entre la ponderación y la pretensión de corrección. La base epistemológica del principio de proporcionalidad es la relación entre medios y fines, por ese motivo la aplicación del principio no puede garantizar la corrección. De hecho, entre el conjunto de las reglas del discurso catalogadas por ALEXY, el principio de ponderación forma parte de aquellas reglas que plantean exigencias de racionalidad que son válidas independientemente de la teoría del discurso. Ellas pueden ser usadas monológicamente y no forman parte de aquellas reglas más específicas que garantizan la imparcialidad. No se ve cómo, entonces, el juicio de ponderación puede satisfacer la pretensión de corrección en sentido fuerte que para el propio ALEXY todo enunciado jurídico plantea. 
Vayamos, para concluir, al asunto central: por qué los jueces no deberían abandonar la perspectiva deontológica cuando deciden conflictos entre derechos. Todo el mundo acepta, por lo menos en los sistemas jurídicos basados en constituciones con derechos firmemente establecidos, que la perspectiva del juez cuando decide una sentencia debe ser primariamente deontológica. Como es obvio, un juez no puede, por ejemplo, condenar a un inocente para evitar grandes disturbios. La función del juez en el sistema jurídico es hacer respetar los derechos. Puede también, y es deseable que lo haga, promover situaciones en las que se respeten más los derechos, pero el juez tiene siempre que respetar él mismo los derechos. No puede, para minimizar las violaciones de derechos, violar ningún derecho. Como NozICK advirtió con claridad en este punto, no es posible pensar en un «utilitarismo de derechos» ${ }^{19}$. Sería un contrasentido. Los derechos funcionan como restricciones laterales (side constraints) para las acciones teleológicas; establecen límites deontológicos a la persecución de lo bueno.

¿Por qué, entonces, cuando este mismo juez reconoce que hay un conflicto entre derechos debería abandonar esa perspectiva deontológica y pasar a ponderar valores? Muchos consideran que pasar a adoptar una perspectiva teleológica-consecuencialista en tales casos es inevitable, otros reconocen que no es inevitable pero la recomiendan como valiosa «en el resquicio que se produce como resultado del conflicto de derechos» ${ }^{20}$.

He intentado mostrar que no es inevitable. Es inevitable solo para quienes tienen una concepción teleológica de los derechos. Por ejemplo, para ALEXY. Dada su concepción de los principios como directrices — como mandatos de optimización- es obvio que todo conflicto posible entre ellos será conceptualizado como exigiendo la ponderación de los valores en conflicto, de manera que la única manera racional de resolverlo consistirá en maximizar la realización de ambos valores. Pero no hay ninguna necesidad de concebir que todos los principios tengan necesariamente esa estructura teleológica y, por tanto, de tener esa concepción teleológica de los derechos.

Para quien defiende una concepción deontológica de los derechos, en cambio, no solo no es inevitable ponderar sino que el conflicto se presenta, en principio, como un conflicto entre «pretensiones de derecho». El argumento empieza antes. Y justamente porque el argumento empieza antes creo que, independientemente de la concepción deontológica específica que se defienda en cada caso, hay más posibilidades de que la decisión sea mejor en términos de racionalidad jurídica ${ }^{21}$. Desde esta perspectiva, es

19 R. Nozick, Anarchy, State and Utopie, Blackwell, 1974, 28 y ss.

20 Martín FARRELL, por ejemplo, reconoce que, en los países que tienen constituciones con derechos firmemente establecidos, el sistema jurídico exige claramente que el juez obre como un deontologista y que así debe hacerlo, pero sostiene que en los casos de conflictos entre derechos el juez debe practicar el cálculo consecuencialista. «Aquí Dworkin no tiene nada que decir, ya que los derechos son cartas de triunfo respecto de la utilidad, pero no - obviamente - respecto de otros derechos. Y es en este tipo de casos que yo sugiero precisamente que el juez debe aplicar el razonamiento consecuencialista». [...] No obstante, alguien podría intentar describir la cuestión de otra forma. Ante dos derechos en conflicto las restricciones se cancelan y el juez puede seguir actuando como un deontologista [...] yo prefiero decir que - en el resquicio que se produce como resultado del conflicto de derechos- el juez obra como un consecuencialista» (M. FARREL, «Los planes económicos y la Corte Suprema», en Filosofía del Derecho y Economía, Buenos Aires, Ediciones La ley, 2006, 11).

21 Juan GARCÍA AMADO sostiene que hay menos rigor argumentativo en la ponderación, porque cuando los jueces ponderan dejan de argumentar sobre lo que verdaderamente guía sus decisiones: las razones y valoraciones que determinan sus elecciones interpretativas. J. A. GARCÍA AMADO, «El juicio de ponderación y sus 
necesario argumentar sustantivamente sobre lo que sería correcto hacer en esa situación, y ello nos fuerza a interpretar y concretizar el significado de los derechos en la situación $^{22}$. Es necesario mostrar que una de las dos normas presuntamente aplicables es la más adecuada para esa situación, y eso supone que estamos teniendo en cuenta todos los rasgos relevantes de la situación, algo que solo podemos hacer a la luz de las normas presuntamente aplicables, que a su vez están siendo concebidas como formando parte de un sistema coherente ${ }^{23}$.

Hay otra razón muy importante para para negar que los jueces deban ponderar. Hasta ahora hemos visto que entender los derechos como valores o entenderlos como normas deontológicas tiene consecuencias muy importantes. Hemos hablado de la distinción entre la «lógica del bien» y sobre la «lógica del deber», pero no hemos dicho lo suficiente sobre la diferencia que hay con respecto a quién razona sobre los derechos usando esas lógicas, si los jueces o los ciudadanos. Este es un aspecto enfatizado en la crítica que HABERMAS dirige a ALEXY. Los ciudadanos pueden y deben ponderar sobre valores y sobre fines, porque los ciudadanos deben legislar. Pero los jueces no deben legislar sino aplicar la ley, por eso no deben ponderar ${ }^{24}$.

\section{BIBLIOGRAFÍA}

AleiniKOFF, Th. A., 1987: «Constitutional Law in the Age of Balancing», Yale Law Journal, 96, núm. 5, 943-1005.

AleXY, R., 1986: Theorie der Grundrechte, Frankfurt: Suhrkamp.

- 2003: «Constitutional Rights, Balancing, and Rationality», Ratio Iuris, 16, núm. 2, 131-140.

Atienza, M., y Manero, J., 1991: «Sobre Principios y Reglas», Doxa. Cuadernos de Filosofía del Derecho, núm. 10.

CALI, B., 2007: «Balancing Human Rights? Methodological Problems with Weights, Scales and Proportions», Human Rights Quarterly, 29, núm. 1, 251-170.

DwORKIN, R., 1978: Taking Rights Seriously, Harvard University Press.

- 2011: Justice for Hedgehogs, Cambridge (Mass.): Harvard University Press.

FARREL, M., 2006: «Los planes económicos y la Corte Suprema», Filosofía del Derecho y Economía, Buenos Aires: Ediciones La Ley, 1-18.

GARCÍA AMADO, J. A., 2006: «El juicio de ponderación y sus partes. Crítica de su escasa relevancia», en R. SANIn RESTEPO (ed.), Justicia Constitucional. El rol de la Corte Constitucional en el Estado, Bogotá: Legis, 120-163.

GardBaum, S., 2010: «A Democratic Defense of Constitutional Balancing», Law and Ethics of Human Rights, 4, núm. 1.

GÜNTHER, K., 1988: Der Sinn für Angemessenheit, Frankfurt: Suhrkamp.

partes. Crítica de su escasa relevancia», en R. SANIN RESTEPO (ed.), Justicia Constitucional. El rol de la Corte Constitucional en el Estado, Bogotá, Legis, 2006, 120-163.

${ }^{22}$ Hay varias posiciones que enfatizan en este proceso, y que no solo provienen de la hermeneútica. Vid., por ejemplo, la defensa del especificacionismo de Christopher Wellman (Ch. H. WeLlman, «On Conflicts between Rights», in Law and Philosophy, vol. 14 (1995), 271-295.

23 Esta es, a muy grandes rasgos, la posición de Klaus GÜNTHER, en la que se basa HABERMAS para criticar a la teoría de ALEXY (K. GÜNTHER, Der Sinn für Angemessenheit, Frankfurt, Suhrkamp, 1988).

${ }^{24}$ No olvidemos que en la posición de ALEXY la defensa de la ponderación va junto con la tesis de que los jueces constitucionales son los «representantes argumentativos» de los ciudadanos. 
HABERMAS, J., 1992: Faktizität und Geltung: Beiträge zur Diskurstheorie des Rechts und des Demokratischen Rechtsstaats, Frankfurt: Suhrkamp.

Herman, B., 1993: «Obligation and Performance», The Practice of Moral Judgment, Harvard University Press, 159-183.

KAnT, I., 1989: La metafísica de las costumbres, trad. Adela CoRTINA, Madrid: Tecnos.

Kumm, M., 2004: «Constitutional Rights as Principles: On the Structure and Domain of Constitutional Justice. A Review Essay on a Theory of Constitutional Rights», International Journal of Constitutional Law, 2, núm. 3, 574-596.

La Torre, M., 2002: «Theories of Legal Argumentation and Concepts of Law. An Approximation», Ratio Iuris, 15, núm. 4, 377-402.

MÖLLER, K., 2007: «Balancing and the structure of constitutional rights», I.Con, vol. 5, núm. 3 , 453-468.

Nozick, R., 1974: Anarchy, State and Utopie, Blackwell.

O’NeILl, O., 2000: «Principles, practical judgment and institutions», Bounds of Justice, Cambridge University Press, 50-64.

— 2007: «Normativity and Practical Reason», Journal of Moral Philosophy, vol. 4 (3), 393-405.

PRIETO SANCHÍs, L., 2003: Justicia constitucional y derechos fundamentales, Madrid: Trotta.

Ross, W. D., 1930: The Right and the Good, Indiana: Hackett Publishing Company, 1988.

TSAKYRAKIS, S., 2009: «Proportionality: An Assault on Human Rights?», International Journal of Constitutional Law, 7, núm. 3, 468-493.

Velasco, M., 2011: ¿Qué es la justicia? Argumentos filosóficos sobre lo justo y lo injusto, Buenos Aires: Eudeba.

Wellman, Ch. H., 1995: «On Conflicts between Rights», Law and Philosophy, vol. 14, 271-295. 